\title{
Upstream Region SNP
}

National Cancer Institute

\section{Source}

National Cancer Institute. Upstream Region SNP. NCI Thesaurus. Code C45575.

An inherited single base substitution in a sequence of eukaryotic DNA located within a region 5 ' to the transcription start site of a gene. This type of single nucleotide polymorphism may affect gene expression if it occurs in the promoter region of a gene and alters the recognition sequence of a specific promoter protein. 